\title{
Phytomolecules investigated for the prevention and treatment of urinary stones
}

\author{
Fatima Ezzahra El oumari ${ }^{1, *}$, Dalila Bousta ${ }^{2}$, Andriy Grafov ${ }^{3}$ and Tarik Sqalli Houssaini $^{1}$ \\ ${ }^{1}$ University Sidi Mohammed Ben Abdellah, Faculty of Medicine and Pharmacy, Fez, Morocco \\ ${ }^{2}$ University Sidi Mohammed Ben Abdellah, Faculty of Sciences Dhar El Mahraz, Fez, Morocco \\ ${ }^{3}$ University of Helsinki, Department of chemistry, Helsinki, Finland
}

\begin{abstract}
Urolithiasis is a recurrent pathology manifested by the stone formation in the urinary system; it has long been treated in traditional medicine by plant remedies. Several studies have provided the efficacy of medicinal plants as well as their chemical compounds against stone formation. The present work aims to summarize the antiurolithiatic effect of phytochemicals, including quercetin, rutin, catechin, diosmin, and thymoquinone. In this context, various databases, including PubMed, Science Direct, Scopus, and google scholar, were searched using keywords like antiurolithiatic bioactive molecules and chemistry of phytomolecules.

The results confirmed that phytochemicals, including particularly flavonoid molecules, could be effective against lithogenesis via different strategies such as decreasing the binding between crystals and cells, decreasing the growth of crystals, and increasing magnesium level. Nevertheless, more studies are required, such as determination of toxicity and clinical studies. This review may help researchers achieve more results about the mechanism and the side effects of phytochemicals administration.
\end{abstract}

Keywords: Urolithiasis; phytomolecules; lithogenesis; toxicity.

\section{Introduction}

Urolithiasis, a recurrent disease known as urinary calculi or urinary stones, are hard deposits of minerals and salt formed anywhere in the urinary tract. We can distinguish 3 terms; nephrolithiasis term used to indicate stones formed in the kidneys. Ureterolithiasis refers to ureteral stones, and Cystolithiasis term means the bladder calculi ${ }^{1}$. This disorder is the outcome of physicochemical steps; the initial step is the nucleation, characterized by the association of free ions into micro-particles after urine supersaturation. The following event is crystal growth, making crystals grow by removing promoters of a stone formation such as uric acid and urate from the urine ${ }^{2}$. The aggregation is the last event, during which the crystals bind to those already established to form larger particles ${ }^{3}$. The etiology of this disease consists of increased excretion of stone-forming components such as calcium, oxalate, urate, cystine, xanthine, and phosphate and decreased urine volume ${ }^{4}$. An excess of vitamin D can cause it, vitamin A deficiency, hyperthyroidism, gout, intestinal dysfunction ${ }^{5}$, and infection by bacteria such as Klebsiella pneumoniae, Pseudomonas and Oxalobacter formigenes ${ }^{6}$. There are other etiological factors such as dietary risk, hot climate, and genetic factors ${ }^{7,8}$.

*Corresponding author: Fatima Ezzahra El oumari Email address: fatimezzahraeloumari@gmail.com DOI: http://dx.doi.org/10.13171/mjc02102271568fee
The treatment is medical or surgical; the medical one is mainly based on applying hygienic and dietary rules, surveillance, and stones' spontaneous expulsion. Among the prescribed drugs for treating stones, there are synthetic drugs like thiazide diuretics(hydrochlorothiazide), alkali (potassium citrate), allopurinol, sodium cellulose phosphate (SCP), penicillamine (Cuprimine), analgesic (diclofenac sodium), bisphosphonates, potassium, phosphate, and probiotics (Oxalobacter formigenes $)^{9}$. For the surgical treatment, among the techniques used, there are: percutaneous lithotripsy (PCNL), extracorporeal shock wave lithotripsy (ESWL), and transurethral lithotripsy (TL) ${ }^{10,11}$. These treatments can lead to a decrease in renal function, hemorrhage, and hypertension. Besides, they are expensive and do not prevent the recurrence of stone formation ${ }^{12,13}$. Moreover, till now, there is no satisfactory drug to treat and prevent urolithiasis.

Medicinal plants possess a wide range of biological activities, such as antidiabetic, anticancer, antiurolithiatic, and analgesic effects ${ }^{14}$. Besides, it exhibits an antimicrobial property, including antibacterial and antifungal activities ${ }^{15}$. In addition, it can also act as an anti-infertile agent ${ }^{16}$.

In folk medicine, urolithiasis has been treated by different herbal formulations. The decoction was the

Received December 29, 2020

Accepted January 29, 2021

Published February 27, 2021 
commonly used mode of herbal remedies ${ }^{17}$. Dried powder, fresh leaves ${ }^{14}$, and juice were also used ${ }^{18}$.

The side effects of medicinal plants and natural molecules are lesser than conventional treatment; therefore, several studies have examined medicinal plants' anti-urolithiatic activity. Its effectiveness is due to its rich phytomolecules. The goal of this work is to summarize some chemical properties of phytomolecules and their antiurolithiatic effects.

\section{Search Methodology}

PubMed, Science Direct, Scopus, and Google scholar databases were searched for bioactive phytomolecules investigated to prevent and treat urolithiasis. For searching, we have used keywords like urolithiasis, anti-urolithiasis, antiurolithiatic bioactive molecules, the chemistry of phytomolecules. We considered that the studies are valuables if they include in vitro, in vivo studies for anti-urolithiatic effects, review, and research articles for bioactive molecules' chemistry. Concerning the selection, collection, and synthesis of data, we have based on the articles' title and abstracts; then, we extracted a standard data form based on the first author's last name and year of publication.

\section{Phytochemicals with anti-urolithiatic activity and its Chemical properties}

Many diseases can be prevented and/or treated by phytomolecules, among them urolithiasis; within this context, multiple studies were carried out for the antiurolithiatic effect of phytoconstituents (Table 1).

Quercetin (pentahydroxyflavone) is one of the phytomolecules investigated for anti-urolithiatic effect. It is a lipophilic molecule with five hydroxyl groups (Figure 1), categorized in flavonol class, synthesized in leaves, flowers, or fruit plant parts, and found in many dietary plants such as Onions ${ }^{19}$, Blueberry ${ }^{20}$, and Mango ${ }^{21}$. Due to the presence of free hydroxyl groups, quercetin has exhibited a strong anti-oxidant activity ${ }^{22}$. Additionally, it is effective against inflammation and diabetes ${ }^{23}$. In an in vitro study, the result showed that the decrease in MDCK (Madin-Darby canine kidney) cell viability and lipid peroxidation were inhibited in the presence of quercetin ${ }^{24}$. Quercetin and hyperoside were studied using Ethylene Glycol Induced calcium oxalate kidney stones in a rat model. The result showed a significant increase in superoxide dismutase and catalase levels; the histopathological examination showed a significant decrease of crystals in the kidneys of quercetin-hyperoside treated group ${ }^{25}$. Additionally, the co-administration of quercetin and betulin (isolated from aerva lanata L.) reduced the risk of stone formation by decreasing oxalate excretion, nucleation, and growth of crystals as well as increasing magnesium level ${ }^{26}$.

Rutin or 3, 3', 4', 5, 7-pentahydroxyflavone-3Rhamnoglucoside is a derivative of quercetin also named quercetin 3-O-rutinoside, it is a bioactive phytomolecule substituted with two sugars: glucose and rhamnose ${ }^{34}$ (Figure 2), it has been studied for several biological activities among them, antihypercholesterolemic ${ }^{35}$, anticancer ${ }^{36}$, antidiabetic ${ }^{37}$, and antimicrobial activity ${ }^{38}$. In addition, rutin exhibits a nephroprotective effect against nephrotoxicity by diminishing the levels of MDA, urea, and creatinine and increasing glutathione peroxidase and superoxide dismutase 39,40 . Rutin has been found to be capable of inhibiting calcium oxalate formation. Additionally, administration of rutin and curcumin has been found to be capable of restoring the normal urinary levels of calcium and oxalate and inhibiting aggregation and growth of calcium oxalate monohydrate crystals 41 . Catechin is another nutraceutical bioactive chemical, chemically named (2S,3R)-2-(3,4 dihydroxyphenyl) chroman-3,5,7triol, has 4 enantiomers which are epicatechin, epicatechin gallate, epigallocatechin, and epigallocatechin gallate (EGCG) (Figure 3), those molecules have been found in many dietary plants such as green tea, blackberries, and apricot. Various studies have demonstrated the antiviral, anti-oxidant, and anti-inflammatory activities of catechin ${ }^{42,43}$. Additionally, epigallocatechin gallate (EGCG) has been reported to protect kidneys against acute kidney injury caused by cardiopulmonary bypass operation ${ }^{44}$. Similarly, and regardless of the cause, EGCG exerts a protective effect against AKI ${ }^{45}$. Antiurolihiatic effect of catechin against stone formation suggested inhibiting renal papillary calcification ${ }^{46}$. In another study, catechin has shown a significant decrease in the number of crystals induced by melamine-cyanuric acid mixture; this effect could be attributed to its inhibitory effect of reactive oxygen species, phospho-P38, and apoptosis ${ }^{48}$. In addition, EGCG has been found to be effective in the prevention of stone formation via inhibiting the expression of alpha-enolase protein and thus decreasing the binding between crystals and MDCK cells $^{49}$.

Diosmin or 3',5,7-trihydroxy-49-methoxyflavone 7rutinoside (Figure 4), is a flavone glycoside compound, belongs to the family of citrus flavonoid, exhibits several remarkable biological activities such as anti-inflammatory, antihypertensive, anti-oxidant, vascular-protecting activity and chemopreventive effect against colon carcinogenesis ${ }^{51}$. This nutraceutical agent exerts a nephroprotective effect by attenuating lipid peroxidation and modulating Bax and $\mathrm{p} 53$ protein expression ${ }^{52}$. In addition, diosmin has been reported to modulate capillaries and vessels diameter of the cortex; it could prevent urolithiasis by keeping the acidic value of urinary $\mathrm{pH}$; its preventive property against stone formation could also be attributed to the decrease of urinary protein level and the increase of potassium and magnesium urinary levels 53,54 . Thymoquinone (2-Isopropyl-5-methyl-1, 4-benzoquinone) (Figure 5) is a nonpolar bioactive phytochemical and a major compound of Nigella Sativa seeds that categorized in monoterpenes class; it 
can be found in other plants like Juniperus Cedrus Webb \& Berthel and Tetraclinis articulate (Vahl) Mast. ${ }^{32}$, it covers a wide range of pharmacological properties which include antioxidant, antiinflammatory, anti-Alzheimer, hepatoprotective, neuroprotective, anticancer, and nephroprotective activity ${ }^{55}$. This phytochemical has been investigated on Ethylene Glycol-Induced urolithiasis in the Rats model. The result of this study indicated that a low dose of thymoquinone $(5 \mathrm{mg} / \mathrm{Kg})$ could be more effective with a significant prophylactic effect against $\mathrm{CaOx}$ stone formation ${ }^{56}$

Table 1. Chemical properties of phytomolecules and their effect on calculi formation.

\begin{tabular}{|c|c|c|c|c|}
\hline Phytochemical & $\begin{array}{c}\text { Molecular } \\
\text { formula }\end{array}$ & $\begin{array}{c}\text { Molecular } \\
\text { weight } \\
\text { g/mol }\end{array}$ & Plant source & Effect on stone formation \\
\hline Quercetin & $\mathrm{C}_{15} \mathrm{H}_{10} \mathrm{O}_{7}$ & 302.23 & $\begin{array}{l}\text { Allium cepa } \mathrm{L} ., \\
\text { Camellia sinensis }(\mathrm{L} .) \\
\text { Kuntze, Moringa oleifera } \\
\text { Lam., Apium graveolens L., } \\
\text { Prunus avium }(\mathrm{L} .) \text { L. } \\
\text { Coriandrum sativum L... }\end{array}$ & $\begin{array}{l}\text { Inhibits the Decrease of lipid peroxidation } \\
\text { and cell viability caused by oxalate }{ }^{24} \text {. } \\
\text { Decrease crystal deposition in kidneys } \\
\text { and urine }{ }^{25} \text {. } \\
\text { Reduce oxidative damage and increase } \\
\text { serum paraoxonase } 1 \text { (PON1) which can } \\
\text { protect kidneys against oxidative stress }{ }^{33} \text {. }\end{array}$ \\
\hline Rutin & $\mathrm{C}_{27} \mathrm{H}_{30} \mathrm{O}_{16}$ & 610.5 & $\begin{array}{l}\text { Ruta graveolens L., Sophora } \\
\text { japonica L., Canna indica } \\
\text { L., Canna edulis } \\
\text { KerGawl... }\end{array}$ & $\begin{array}{l}\text { Decrease MDA, urea, and creatinine. } \\
\text { Increase glutathione peroxidase and } \\
\text { superoxide dismutase }{ }^{39} \text {. } \\
\text { Restores normal calcium and oxalate } \\
\text { urinary levels }{ }^{41} \text {. }\end{array}$ \\
\hline Catechin & $\mathrm{C}_{15} \mathrm{H}_{14} \mathrm{O}_{6}$ & 290.27 & $\begin{array}{l}\text { Arrabidaea } \\
\text { brachypoda Bureau, } \\
\text { Rhizophora mangle L. } \\
\text { Camellia sinensis (L.) } \\
\text { Kuntze, } \\
\text { Actinidia deliciosa (A.Chev.) } \\
\text { C.F.Liang \& A.R.Ferguson, } \\
\text { Malus pumila Mill... }\end{array}$ & 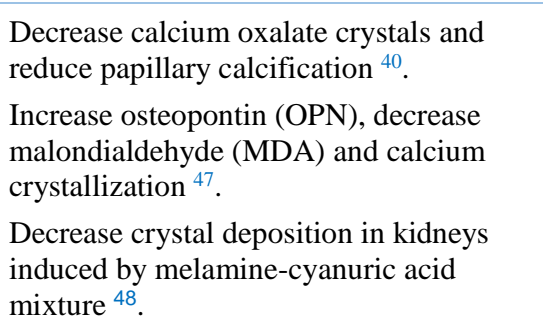 \\
\hline $\begin{array}{l}\text { Epigallocatechin } \\
\text { gallate }\end{array}$ & $\mathrm{C}_{22} \mathrm{H}_{18} \mathrm{O}_{11}$ & 458.4 & $\begin{array}{l}\text { Camellia sinensis }(\mathrm{L} .) \\
\text { Kuntze, } \\
\text { Theobroma cacao L... }\end{array}$ & $\begin{array}{l}\text { Decrease the binding between crystals and } \\
\text { MDCK cells by inhibiting the expression } \\
\text { of alpha-enolase protein }{ }^{49} \text {. } \\
\text { Reduce free radical production and } \\
\text { oxalate excretion in urine }{ }^{50} \text {. }\end{array}$ \\
\hline Diosmin & $\mathrm{C}_{28} \mathrm{H}_{32} \mathrm{O}_{15}$ & 608.5 & $\begin{array}{l}\text { Citrus lemon (L.), Citrus } \\
\text { reticulate Blanco, and Citrus } \\
\text { sinensis (L. Osbeck) } \\
\text { Teucrium gnaphalodes } \\
\text { L'Hér... }^{54} \text {. }\end{array}$ & $\begin{array}{l}\text { Increase urinary magnesium and } \\
\text { potassium levels }{ }^{52} \text {. } \\
\text { Prevent stone formation by attenuating } \\
\text { lipid peroxidation and modulating Bax } \\
\text { and p53 proteins expression }{ }^{53} \text {. }\end{array}$ \\
\hline Thymoquinone & $\mathrm{C}_{10} \mathrm{H}_{12} \mathrm{O}_{2}$ & 164.2 & $\begin{array}{l}\text { Nigella Sativa L., Nigella } \\
\text { arvensis L., Juniperus } \\
\text { Cedrus Webb \& Berthel. and } \\
\text { Tetraclinis articulate (Vahl) } \\
\text { Mast. }{ }^{32}\end{array}$ & $\begin{array}{l}\text { Reduce } \mathrm{CaOx} \text { crystal deposition in the } \\
\text { kidneys }{ }^{56} \text {. } \\
\text { Decrease serum creatinine and urea levels. } \\
\text { Reduce lipid peroxidation, } \\
\text { malondialdehyde (MDA) and } 8 \text { - } \\
\text { isoprostane }{ }^{57} \text {. }\end{array}$ \\
\hline
\end{tabular}<smiles>O=c1c(O)c(-c2ccc(O)c(O)c2)oc2cc(O)cc(O)c12</smiles>

Figure 1. Chemical structure of quercetin<smiles>O=c1c(O[C@@H]2O[C@H](O)[C@H](O)[C@H](O)[C@H](O)[C@H](O)[C@H]2O)c(-c2ccc(O)c(O)c2)oc2cc(O)cc(O)c12</smiles>

Figure 2. Chemical structure of rutin 
<smiles>Oc1cc(O)c2c(c1)O[C@H](c1ccc(O)c(O)c1)[C@H](O)C2</smiles>

(-)- Epicatechin<smiles>O=C(O[C@@H]1Cc2c(O)cc(O)cc2O[C@H]1c1ccc(O)c(O)c1)c1cc(O)c(O)c(O)c1</smiles>

(-)- Epicatechin gallate<smiles>Oc1cc(O)c2c(c1)O[C@H](c1cc(O)c(O)c(O)c1)[C@H](O)C2</smiles>

(-)- Epigallocatechin<smiles>O=C(O[C@@H]1Cc2c(O)cc(O)cc2O[C@H]1c1cc(O)c(O)c(O)c1)c1cc(O)c(O)c(O)c1</smiles>

(-)-Epigallocatechin gallate

Figure 3. Chemical structure of the four enantiomers of catechin

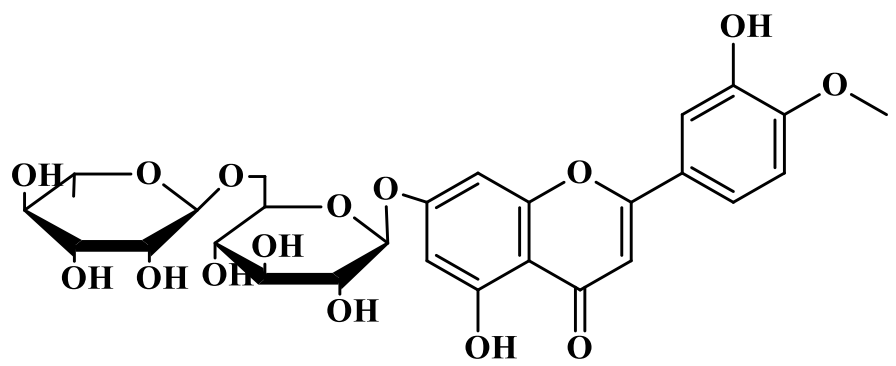

Figure.4 Chemical structure of Diosmin

Urinary stones are a recurrent disorder that can lead to chronic kidney diseases (CKD) and acute kidney injury (AKI) ${ }^{58}$. The actual treatments (medical or surgical) described to patients with urinary calculi are quite restricted. Some drugs like alkali-citrate are described to patients to prevent calculi formation, but their efficacy is low. Thus, they are not entirely preventing urolithiasis ${ }^{59}$. Medicinal plants represent an essential source of prophylactic and therapeutic remedies to treat several disorders, including urinary stones.

In vitro and in vivo studies on the preventive and therapeutic effect of phytomolecules revealed that the mentioned chemicals could inhibit stone formation using various mechanisms, including decreasing crystal deposition in the kidneys and increasing glutathione peroxidase superoxide dismutase, and cell viability ${ }^{24,58}$. Phytochemicals also use other strategies to prevent urinary stone formation, such as<smiles>CC1=CC(=O)C(C(C)C)=CC1=O</smiles>

Figure.5 Chemical structure of thymoquinone

suppression of the bound between crystals and tubular epithelial cells, Decreasing MDA, and regulation of serum PON1 33,47. The mechanism by which thymoquinone can manage kidney stones is still unknown. But as some studies have demonstrated it, thymoquinone can probably inhibit urolithiasis by decreasing lipid peroxidation and MDA, as well as reducing the serum levels of creatinine and urea ${ }^{57}$.

The result obtained from the available literature showed that all of the phytochemicals are nutraceutical. They can be effective against stone formation through several mechanisms, among them the antioxidant activity. This later is strongly correlated to the anti urolithiatic effect. Unfortunately, the current results cannot confirm the effectiveness of these molecules without testing their toxicity and their effects on human health. Further research is needed to establish more results about the safety and efficacy of patients with urinary stones. 


\section{Conclusion}

Many pharmaceutical drugs are used to treat urinary stones, such as potassium citrate and sodium cellulose phosphates. However, most of them are quite restricted and present many side effects; therefore, till now, there is no satisfactory drug to treat and prevent urolithiasis. Several studies have been demonstrated the efficacy of medicinal plants and their compounds on the prevention and management of urinary stones. In this work, we have summarized the efficacy of phytochemicals investigated to prevent and manage urinary calculi. The result obtained from the available literature showed that all of the phytochemicals are nutraceutical and can be found in many dietary plants. Therefore, phytochemicals such as quercetin, catechin, and thymoquinone have been considered as promising natural molecules for the inhibition and management of stone formation. It can use different strategies for preventing and treating urinary stones; it can act on all stone formation steps by inhibiting the nucleation, growth, and aggregation of calcium oxalate crystals. Other mechanisms are increasing urinary citrate and magnesium levels, decreasing urinary calcium and oxalate levels, reducing freeradical production, and diminishing the bound between crystals and tubular epithelial cells. A new drug can be developed from these phytochemicals. However, more studies are required to determine these compounds' validity and safety in patients with urolithiasis.

\section{Conflicts of interest}

The authors declare that no conflict of interest could influence the work reported in this paper.

\section{Funding support}

The authors are grateful for the financial support of the project H2020-MSCA-RISE-Marie SkłodowskaCurie Actions (MSCA), Research and Innovation Staff Exchange (RISE), Project Acronym: VAHVISTUS - Project Number: 734759.

\section{Acknowledgment}

The national center's present work was funded for scientific and technical research (CNRST) in Rabat, Morocco.

\section{References}

1- O. S. Aduayi, O.C. Famurewa, Cystolithiasis with coexisting nephrolithiasis: A radiodiagnostic discovery in an adult Nigerian male with lower urinary tract symptoms, J Med Investig Pract, 2015, 10, 30-2.

2- D. J. Kok, S. R. Khan, Calcium oxalate nephrolithiasis, a free or fixed particle disease, Kidney Int., 1994, 46, 847-854.

3- G. Farell, E. Huang, S. Y. Kim, R. Horstkorte, J. C. Lieske, Modulation of proliferating renal epithelial cell affinity for calcium oxalate monohydrate crystals, J Am Soc Nephrol., 2004, 15, 3052-3062.

4- A. K. Shukla, S. Shukla, A. Garg, S. Garg, A review on the anti-urolithiatic activity of herbal folk plants, Asian Journal of Biomaterial Research, 2017, 3, 1-11.

5- S. K. Mekap, S. Mishra, S. Sahoo, P. K. Panda, Antiurolithiatic activity of Crataeva magna Lour bark, Indian Journal of Natural Products and Resources, 2011, 1, 28-33.

6- A. L. Schwaderer, A. J. Wolfe, The association between bacteria and urinary stones, Ann Transl Med., 2017, 5, 32.

7- V. Romero, H. Akpinar, D. G. Assimos, Kidney Stones: A Global Picture of Prevalence, Incidence, and Associated Risk Factors Kidney Stones: A Global Perspective, Reviews in urology, 2010, 12, 86-96.

8- S. Gindi, T. Methra, B. R. Chandu, Antiurolithiatic and in vitro anti-oxidant activity of leaves of Ageratum conyzoides in rat, World J. Pharm., 2013, 2, 636-649.

9- K. Mikawlrawng, S. Kumar, Current scenario of urolithiasis and the use of medicinal plants as antiurolithiatic agents in Manipur (North East India): A Review, International Journal of Herbal Medicine, 2014, 2, 1-12.

10-N. L. Miller, J. E. Lingeman, Management of kidney stones, Br. Med. J., 2007, 334, 468-472.

11-R. P. Terlecki, J. A. Triest, A contemporary evaluation of the auditory hazard of extracorporeal shock wave lithotripsy, Urology, 2007, 70, 898-899.

12-J. R. S. Tabuti, K. A. Lye, S. S. Dhillion, Traditional herbal drugs of Bulamogi, Uganda: plants, use and administration, J. Ethnopharmacol., 2003, 88, 19-44.

13-S. Lipismita, K. P. Ashok, M. Chinmoy, Nutritional strategies to prevent urolithiasis in animals, Veterinary World, 2011, 4, 142-144.

14-M. Birjees, M. Ahmad, M. Zafar, S. Nawaz, S. Jehanzeb, F. Ullah, W. Zaman, Traditional knowledge of wild medicinal plants used by the inhabitants of Garam Chashma valley, district Chitral, Pakistan, Acta Ecologica Sinica, 2021.

15-F. Ulla, A. Ayaz, S. Saqib, W. Zaman, M. A. Butt, A. Ullah, Silene conoidea L.: A review on its systematic, ethnobotany and phytochemical profile, Plant Science Today, 2019, 6, 373-382.

16-W. Zaman, M. Ahmad, M. Zafar, H. Amina, F. Ullah, S. Bahadur, A. Ayaz, S. Saqib, N. Begum, S. Jahan, The quest for some novel antifertility herbals used as male contraceptives in district Shangla, Pakistan. Acta Ecologica Sinica, 2020, 40, 102-112.

17-M. Ghourri, L. Zidane, A. Douira, Catalogue des plantes médicinales utilisées dans le traitement de la lithiase rénale dans la province de Tan-Tan (Maroc saharien), Int. J. Biol. Chem. Sci., 2013, 7, 1688-1700. 
18-K. Agarwal, R. Varma, Ethnobotanical study of antilithic plants of Bhopal district, Journal of Ethnopharmacology, 2015, 174, 17-24.

19-K. Nemeth, M. K. Piskuła, Food content, processing, absorption and metabolism of onion flavonoids, Crit. Rev. Food Sci. Nutr., 2007, 47, 397-409.

20-W. Zeng, S. Y. Wang, Oxygen radical absorbing capacity of phenolics in blueberries, cranberries, chokenberries and lingonberries, J. Agric. Food Chem., 2003, 51, 502-509.

21-N. Berardini, R. Fezer, J. Conrad, U. Beifuss, R. Carle, A. Schieber, Screening of mango (Mangifera indica L.) cultivars for their contents of flavonol O- and xanthone C-glycosides, anthocyanins and pectin, J. Agric. Food Chem., 2005, 53, 1563-1570.

22-H. Liu, L. Zhang, S. P. Lu, Evaluation of antioxidant and immunity activities of quercetin in isoproterenol-treated rats, Molecules, 2012, 17, 4281-4291.

23-M. Bule, A. Abdurahman, S. Nikfar, M. Abdollahi, M. Amini, Antidiabetic effect of quercetin: A systematic review and meta-analysis of animal studies, Food Chem. Toxicol., 2019, 125, 494-502.

24-H. K. Park, B. C. Jeong, M. K. Sung, Reduction of oxidative stress in cultured renal tubular cells and preventive effects on renal stone formation by the bioflavonoid quercetin, J. Urol., 2008, 179, 1620-1626.

25-W. Zhu, Y. F. Xu, Y. Feng, B. Peng, J. P. Che, M. Liu, J. H Zheng, Prophylactic effects of quercetin and hyperoside in a calcium oxalate stone forming rat model, Urolithiasis, 2014, 42, 519-526.

26-B. M. Dinnimath, S. S. Jalalpure, U. K. Patil, Antiurolithiatic activity of natural constituents isolated from Aerva lanata, Journal of Ayurveda and Integrative Medicine, 2017, 8, 226-232.

27-A. V. A. David, R. Arulmoli, S. Parasuraman, Overviews of biological importance of quercetin: A bioactive flavonoid, Phcog. Rev., 2016, 10, 84-89.

28-L. S. Chua, A review on plant-based rutin extraction methods and its pharmacological activities, Journal of Ethnopharmacology, 2013, $150,805-817$.

29-G. A. C. Ribeiroa, C. Q. Rochaa, W. B. Veloso, R. N. Fernandesa, I. S. Silvab, A. A. Tanaka, Determination of the catechin contents of bioactive plant extracts using disposable screenprinted carbon electrodes in a batch injection analysis (BIA) system, Microchemical Journal, 2019, 146, 1249-1254.

30-P. V. Gadkari, M. Balaraman, Catechins: Sources, extraction and encapsulation: A review, food and bioproducts processing, 2015, 93, 122-138.

31-E. Cione, C. La Torre, R. Cannataro, M. C. Caroleo, P. Plastina, L. Gallelli, Quercetin, Epigallocatechin Gallate, Curcumin, and
Resveratrol: From Dietary Sources to Human MicroRNA Modulation, Molecules, 2020, 25, 63.

32-J. Taborsky, M. Kunt, P. Kloucek, J. Lachman, V. Zeleny, L. Kokoska, Identification of potential sources of thymoquinone and related compounds in Asteraceae, Cupressaceae, Lamiaceae, and Ranunculaceae families, Open Chem., 2012, 10, 1899-1906.

33-E. A. Cladera, A. Nadal-Casellas, Y. GómezPérez, I. Gomila, R.M. Prieto, A.M. Proenza, I. Lladó, Phytotherapy in a rat model of hyperoxaluriahe antioxidant effects of quercetin involve serum paraoxonase 1 activation, Exp. Biol. Med., 2011, 236, 1133-1138.

34-S. Sharma, A. Ali, J. Ali, J. K. Sahni, S. Baboota Rutin: therapeutic potential and recent advances in drug delivery, Expert Opinion on Investigational Drugs, 2013, 22, 1063-1079.

35- A. Kanashiro, D. C. Andrade, L. M. Kabeya, Modulatory effects of rutin on biochemical and hematological parameters in hypercholesterolemic Golden Syrian hamsters, An. Acad. Bras. Cienc., 2009, 81, 67-72.

36-J. P. Lin, J. S. Yang, J. J. Lin, K. C. Lai, H. F. Lu, C. Y. Ma, C. Wu, K. C. Wu, F. S. Chueh, W. G. Wood, J. G. Chung, Rutin inhibits human leukemia tumor growth in a murine xenograft model in vivo, Environmental Toxicology, 2012, 27, 480-484.

37-N. T. Niture, A. A. Ansari, S. R. Naik, Antihyperglycemic activity of rutin in streptozotocininduced diabetic rats: an effect mediated through cytokines, antioxidants and lipid biomarkers, Indian Journal of Experimental Biology, 2014, 52, 720-727.

38-S. Wang, C. Wang, L. Gao, H. Cai, Y. Zhou, Y. Yang, C. Xu, W. Ding, J. Chen, I. Muhammad, X. Chen, X. He, D. Liu, Y. Li, Rutin inhibits Streptococcus suis biofilm formation by affecting CPS biosynthesis, Frontiers in Pharmacology, 2017, 8, 1-12.

39-F.M. Kandemir, M. Ozkaraca, B. A Yildirim, B. Hanedan, A. Kirbas, K. Kilic, E. Aktas, F. Benzer, Rutin attenuates gentamicin-induced renal damage by reducing oxidative stress, inflammation, apoptosis, and autophagy in rats, Renal Failure, 2015, 37, 518-525.

40-W. Zhai, J. Zheng, X. Yao, B. Peng, M. Liu, J. Huang, G. Wang, Y. Xu, Catechin prevents the calcium oxalate monohydrate induced renal calcium crystallization in NRK-52E cells and the ethylene glycol induced renal stone formation in rat, BMC Complement. Altern. Med., 2013, 13, $1-11$.

41-J. Ghodasara, A. Pawar, C. Deshmukh, Inhibitory effect of rutin and curcumin on experimentallyinduced calcium oxalate urolithiasis in rats, Pharmacognosy Res., 2011, 2, 388-392.

42-K. Kaihatsu, M. Yamabe, Y. Ebara, Antiviral Mechanism of Action of Epigallocatechin-3-Ogallate and Its Fatty Acid Esters, Molecules, 2018, 23, 2475. 
43-Y. Shirakami, M. Shimizu, Possible Mechanisms of Green Tea and Its Constituents against Cancer, Molecules, 2018, 23, 2284.

44-S. Y. Lin, L. Kang, C. Z. Wang, H. H. Huang, T. L. Cheng, H. T. Huang, M. J. Lee, Y. S. Lin, M. L. Ho, G. J. Wang, Epigallocatechin-3Gallate (EGCG) Enhances Osteogenic Differentiation of Human Bone Marrow Mesenchymal Stem Cells, Molecules, 2018, 23, 3221.

45-S. T. Chen, L. Kang, C. Z. Wang, P. J. Huang, H. T. Huang, S. Y. Lin, S. H. Chou, C. C. Lu, P. C. Shen, Y. S. Lin, Epigallocatechin-3-Gallate Decreases Osteoclastogenesis via Modulation of RANKL and Osteoprotegrin, Molecules, 2019, 24, 156.

46-G. H. Bao, J. Xu, F. L. Hu, X. C. Wan, S. X. Deng, J. Barasch, EGCG inhibit chemical reactivity of iron through forming an NgalEGCG-iron complex, Biometals, 2013, 26, 1041-50.

47-F. Grases, R. M. Prieto, R. A. Fernandez-Cabot, A. Costa-Bauzá, F. Tur, J. J. Torres, Effects of polyphenols from grape seeds on renal lithiasis, Oxid. Med. Cell. Longev., 2015, 1-6.

48-X. Li, G. Wu, P. Shang, Anti-nephrolithic potential of catechin in melamine-related urolithiasis via the inhibition of ROS, apoptosis, phospho-p38 and osteopontin in male SpragueDawley rats, Free Radical Research, 2015, 49,1249-1258.

49-R. Kanlaya, N. Singhto, V. Thongboonkerd, EGCG decreases binding of calcium oxalate monohydrate crystals onto renal tubular cells via decreased surface expression of alpha-enolase, J. Biol. Inorg. Chem., 2016, 21, 339-346.

50-B. C. Jeong, B. S. Kim, J. I. Kim, H. H. Kim, Effects of green tea on urinary stone formation in vivo and in vitro study, J. Endourol., 2006, 20, 356-361.

51-A. Bogucka-Kocka, M. Woźniak, M. Feldo, J. Kocki, K. Szewczyk, Diosmin-Isolation
Techniques, Determination in Plant Material and Pharmaceutical Formulations, and Clinical Use, Nat. Prod. Commun., 2013, 8.

52-M. U. Rehman, M. Tahir, A. Quaiyoom Khan, R. Khan, A. Lateef, O. O. Hamiza, F. Ali, S. Sultana, Diosmin protects against trichloroethylene-induced renal injury in Wistar ratslausible role of p53, Bax and caspases, Br. J. Nutr., 2013, 110, 699-710.

53-A. Noorafshan, S. Karbalay-Doust, F. Karimi, Diosmin reduces calcium oxalate deposition and tissue degeneration in nephrolithiasis in rats: A stereological study, Korean J. Urol., 2013, 54, 252-257.

54-V. V. Prabhu, D. Sathyamurthy, A. Ramasamy, S. Das, M. Anuradha, S. Pachiappan, Evaluation of protective effects of diosmin (a citrus flavonoid) in chemical-induced urolithiasis in experimental rats, Pharm. Biol., 2016, 54, 1513-1521.

55-A. Ahmad, R. K. Mishra, A. Vyawahare, A. Kumar, M. U. Rehman, W. Qamar, R. Khan, Thymoquinone (2-Isopropyl-5-methyl-1, 4benzoquinone) as a chemopreventive/anticancer agent: Chemistry and biological effects, Saudi Pharm. J., 2019, 27, 1113-1126.

56-M. Hajzadeh, N. Mohammadian, Z. Rahmani, F. B. Rassouli, Effect of thymoquinone on ethylene glycol-induced kidney calculi in rats, Urol. J., 2008, 5, 149-155.

57-P. Hayatdavoudi, A. Khajavi Rad, Z. Rajaei, M. A. R. Hadjzadeh, Renal injury, nephrolithiasis and Nigella sativa: A mini review, Avicenna J Phytomed., 2016, 6, 1-8.

58-X. Tang, J. C. Lieske, Acute and chronic kidney injury in nephrolithiasis, Curr Opin Nephrol Hypertens., 2014, 23, 385-390.

59-D. R. Mandavia, M. K. Patel, J. C. Patel, A. P. Anovadiya, S. N. Baxi, C. R. Tripathi, Antiurolithiatic effect of ethanolic extract of Pedalium murex linn. fruits on ethylene glycolinduced renal calculi, Urol. J., 2013, 10, 946-952. 